\title{
Investigating the Effect of Ultrasonication on the Molecular Structure of Potato Starch Using Synchrotron- based Infrared Spectroscopy
}

\author{
Rhowell N. Tiozon Jr. ${ }^{1(D)}$, Aldrin P. Bonto ${ }^{1,2}, *^{(D)}$, Jann Andre H. Padua ${ }^{1,4}$, Ellaine Grace A. Elbo ${ }^{1(D)}$, \\ Justin Rommel Sampang 1(i), Kanokwan Kamkajon 5(D), Drexel H. Camacho 1,3 (D), Kanjana \\ Thumanu 5,*iD
}

1 Chemistry Department, De La Salle University, 2401 Taft Avenue, Manila 0922 Philippines; rhowell_tiozon@dlsu.edu.ph (R.N.T); aldrin.bonto@dlsu.edu.ph (A.P.B); jann_padua@dlsu.edu.ph (J.A.H.P); ellaine_elbo@dlsu.edu.ph (E.G.E), jrcsampang@gmail.com (J.R.S), drexel.camacho@dlsu.edu.ph (D.H.C);

2 Department of Chemistry, College of Science, España Boulevard, Manila 1008, Philippines; apbonto@ust.edu.ph (A.P.B.);

3 Organic Materials and Interfaces Unit, CENSER, De La Salle University, 2401 Taft Avenue, Manila 0922 Philippines; drexel.camacho@dlsu.edu.ph (D.H.C.);

4 Basic Education Department, De La Salle Araneta University, Victoneta Avenue, Malabon 1476 Philippines; jann_padua@dlsu.edu.ph (J.A.H.P.);

5 Synchrotron Light Research Institute, Mueang District, Nakhon Ratchasima 30000 Thailand; kanjanat@slri.or.th (K.T.); numfon.001@gmail.com (K.K.);

* Correspondence: aldrin.bonto@dlsu.edu.ph (A.P.B.); apbonto@ust.edu.ph (A.P.B.); kanjanat@ slri.or.th (K.T.);

Received: 11.04.2021; Revised: 15.09.2021; Accepted: 19.09.2021; Published: 19.11.2021

\begin{abstract}
For the first time, in this paper, synchrotron-based Fourier transform infrared spectroscopy characterized the changes in the short-order range of potato starch after ultrasonication. Ultrasonic treatment caused cracks and fissures on potato starch granules. Simultaneously, size exclusion chromatography revealed that the ultrasonic treatment having $53 \mathrm{kHz}$ did not induce scissoring of the glycosidic bond of starch. Differential scanning calorimetry showed decreased thermal parameters (To, $\mathrm{Tp}$ and $\Delta \mathrm{H}$ ) of potato starch, indicating a disorder in the starch molecule. Furthermore, synchrotronbased FTIR gives insights on the loosening of short-range order of potato starch as reported by the disruption of the crystalline region of potato starch.
\end{abstract}

Keywords: ultrasound; potato starch; starch granules; synchrotron radiation; FTIR microspectroscopy. (C) 2021 by the authors. This article is an open-access article distributed under the terms and conditions of the Creative Commons Attribution (CC BY) license (https://creativecommons.org/licenses/by/4.0/).

\section{Introduction}

Among the many botanical starch sources, potato starch is an excellent raw material in food processing, which use as a thickening, stabilizing, gelling, and water-holding agent [1]. However, the inherent properties of native starch limit its application in some industrial food processes, including low shear resistance, low thermal resistance, low solubility, high viscosity, and a tendency toward retrogradation [2]. To overcome these disadvantages, potato starch has been exposed to various physical modifications such as heat-moisture treatment [3], electric field [4], microwave irradiation [5, 6], plasma treatment [7], gamma irradiation [8], and ultrasonication [9].

Among these physical modifications, ultrasonication, also referred to as ultrasonic treatment (UT), has been employed to potato starch, causing an impact on its morphology, 
molecular structure, and functional properties. Ultrasound generates fluid mixing and shear forces; thus, UT of potato starch is generally conducted in an aqueous or alcoholic solution. Zhu (2015) elaborates on the mechanisms of UT in aqueous starch solution, which begins when sinusoidal waves pass through the water medium producing a continuous wave-type movement. The generated wave motion then initiates the mixing of the liquid, and the process creates microbubbles from the existing dissolved gas. These microbubbles shrink and explode during the compression cycle. Several periods of compression and rarefaction generate powerful liquid jets or microjets. These microjets facilitate porous potato starch formation $[9,11-15]$.

Moreover, porous starch has a larger surface area and high pore volume utilizing it as a suitable carrier for flavor, probiotics, plant oil, and antioxidants [16]. In terms of molecular structure, UT instigated chain cleavage in potato starch molecules, leading to the decrease of average molecular weight $[17,18]$. Mechanochemical effects and radical reaction caused the chain scissoring leading to starch degradation [19]. Other starch properties such as viscosity $[14,20]$ and relative crystallinity $[21,22]$ are affected by UT

Several techniques measure the crystallinity of potato starch. These techniques include $\mathrm{X}$-ray diffraction, differential scanning calorimetry, ${ }^{13} \mathrm{C}$ cross-polarization magic angle spinning nuclear magnetic resonance spectroscopy, and Fourier transform infrared spectroscopy (FTIR) with attenuated total internal reflectance. Of all these characterization techniques, FTIR is readily available, convenient, and non-destructible to measure starch crystallinity [23]. Moreover, FTIR is used to measure biochemical and biophysical attributes in a wide range of starchy foods in the near-infrared and mid-infrared regions [24]. Starch has relevant functional groups typically located at 2900-3000 cm-1 for C-H stretching, 1100-1150 cm-1 for C-O, C-C, and C-O-H stretching 1100- $900 \mathrm{~cm}^{-1}$ for C-O-H bending. Specifically, the peak at $1022 \mathrm{~cm}^{-1}$ seems to increase in more amorphous samples, whereas the bands at 1000 and $1047 \mathrm{~cm}^{-1}$ become more defined in more crystalline samples. Because of this, the values of peak ratios $\left(1022: 1000 \mathrm{~cm}^{-1}\right.$ and $\left.1047: 1022 \mathrm{~cm}^{-1}\right)$ represent the short-range ordered molecular structure of starch [23].

Most research only uses conventional thermal source FTIR in studying the starch structure. Compared to traditional FTIR, synchrotron-based FTIR provides high spatial resolution, a better signal-to-noise ratio, and a shorter data acquisition time [25]. Furthermore, synchrotron source FTIR is much brighter than conventional thermal sources resulting in a very high resolution with an increase of up to two (or even more) orders of improved magnitude in signal intensity [26, 27]. To the best of our knowledge, there is no study on the use of synchrotron source FTIR to measure the changes in the crystallinity of ultrasonic-treated potato starch. The study measured the relative crystallinity of ultrasonicated potato starch using synchrotron-based infrared spectroscopy and differential scanning calorimeter. Also, the morphology and molecular structure of ultrasonicated potato starch were determined.

\section{Materials and Methods}

\subsection{Sonication procedure.}

In a centrifuge tube, $1.0 \mathrm{~g}$ of potato starch (Sigma Aldrich, U.S.A.) was mixed with 10 $\mathrm{mL}$ of distilled water. Then, the mixture was subjected to ultrasonic wave treatment for 10, 20, and 30 minutes in an ultrasonic bath (Soner 206H, Rocker Scientific Co., Ltd) with an operating frequency of $53 \mathrm{kHz}$ and ultrasonic power of $180 \mathrm{~W}$. During this treatment, the water 
temperature was kept constant by adding ice to the ultrasonic bath avoiding starch gelatinization during the sonication process. The sonicated starch was oven-dried at $35{ }^{\circ} \mathrm{C}$ for 12 hours.

\subsection{Morphology through scanning electron microscopy.}

The morphology of sonicated potato starch granules was observed using scanning electron microscopy (JSM 5310, JEOL SEM) at 20kV. The gold-coated outer surface on the interior of the kernel was observed at 1000 magnification.

\subsection{Analysis of sonicated starch by HPSEC.}

Molecular components of raw and sonicated potato starches were analyzed using highperformance size exclusion chromatography (HPSEC). The samples (10.0 mg) were dissolved in $5.0 \mathrm{~mL}$ dimethyl sulfoxide (DMSO) by heating at $100{ }^{\circ} \mathrm{C}$ for $60 \mathrm{mins}$, then cooled down to room temperature. The samples were filtered through $0.45-\mu$ m nylon syringe filters. HPSEC was performed by the PL aqua gel-OH column $(7.5 \times 300 \mathrm{~mm}, 8 \mu \mathrm{m})$ (Agilent, USA). Analytical HPLC apparatus consisted of a quaternary pump (Agilent 1260 Infinity II) and a refractive index detector (Agilent 1260 Infinity II) autoinjector, and analysis was performed in HP Chem Station software. The column temperature and detector temperature were set to 40 ${ }^{\circ} \mathrm{C}$, and the solvent (distilled water) was pumped at a flow rate of $0.3 \mathrm{~mL} / \mathrm{min}$. The set injection volume is $10 \mu \mathrm{l}$. Molecular weights of starch samples were calculated using a series of pullulan polysaccharides (PL2090-0101) as standards. The pullulan standards' molecular weights were as follows: 642000, 337000, 194000, 107000, 47100, 22000, 9800, and 6100. Calibration calculation and plot of pullulan were found in the supplementary data.

\subsection{Thermal properties.}

Samples $(4.0 \mathrm{mg})$ with water $(8.0 \mu \mathrm{L})$ were scanned from 25 to $110{ }^{\circ} \mathrm{C}$ at a rate of $10^{\circ} \mathrm{C} / \mathrm{min}$ in a sealed, hermetic aluminum pan using a differential scanning calorimeter (DSC), TA Instrument model DSC250. For all measurements, the thermogram was recorded with an empty pan as a reference. Thermal transition parameters [enthalpy of gelatinization $(\Delta H)$, onset temperature $\left(\mathrm{T}_{\mathrm{o}}\right)$, and peak temperature $\left(\mathrm{T}_{\mathrm{p}}\right)$ ] were analyzed using Trios Software. All data are average of duplicate measurements with standard deviation.

\subsection{FTIR Instrumentation and spectral collection.}

Potato samples were ball milled into a fine powder and dried overnight at $30^{\circ} \mathrm{C}$. The characterization of samples was done by synchrotron-based FTIR microspectroscopy. Native and sonicated potato starch samples were prepared using a diamond anvil cell, which is a highpressure cell permitting to operate and adjust under a microscope for transmission studies. Spectral data were collected at an infrared microspectroscopy beamline (BL4.1 Infrared Spectroscopy and Imaging) at the Synchrotron Light Research Institute (SLRI). Spectra were acquired with an SR-FTIR (Hyperion 2000, Bruker Optics, Ettlingen, Germany) coupled with an Infrared microscope (Hyperion 2000, Bruker) using the 36x objective. The detector of the infrared microscope was liquid nitrogen-cooled mercury cadmium telluride (Narrowband MCT) detector (100 $\mu \mathrm{m}$ in size). The measurements were performed in transmission mode, using an aperture size of $20 \times 20 \mu \mathrm{m}^{2}$ with a spectral resolution of $4 \mathrm{~cm}^{-1}$, with 64 scans coadded. Spectral acquisition and instrument control were performed using OPUS 7.2 software 
(Bruker Optics Ltd, Ettlingen, Germany). The spectral changes of the functional groups were performed at the integral area of each peak.

Data prepossessing and analysis of FTIR spectra were done with the software OPUS 7.2 to determine the integrated peak area of carbohydrate $\left(1200-960 \mathrm{~cm}^{-1}\right)$ and the ratios of the crystalline to amorphous peaks (around $1047 \mathrm{~cm}^{-1}$ and $1022 \mathrm{~cm}^{-1}$ ) that are used for quantifying the arrangement of the carbohydrate structure. The whole spectra $\left(4000-800 \mathrm{~cm}^{-1}\right)$ were the first baseline -corrected by using a rubber band correction algorithm and then were normalized by applying vector normalization to reduce the effect of different radiation absorption due to the variation of sample thickness.

\subsection{Statistical analysis.}

Statistical analysis was carried out using one-way ANOVA with Tukey's test as a posthoc analysis at $\alpha=0.05 \%$ or $0.01 \%$. All statistical analyses were done using online freeware ASTATSA (https://astatsa.com/OneWay_Anova_with_TukeyHSD/).

\section{Results and Discussion}

\subsection{Effect of sonication on the morphology of potato starch granules.}

The SEM micrographs depicted the surface morphology of potato starch granules, both the native and ultrasonic treated variants, as shown in Figure 1. Native potato starch (Fig 1A) has smooth, large-sized, and oval-shaped starch granules, which are unique compared to other starch botanical origins such as corn, rice, and wheat [28, 29]. Figure 1B-D depicted the potato starch granules' morphologies treated for 10, 20, and 30-minute treatments. The granular surface of ultrasonic-treated potato starches had depressions, pits, and fissures that accounted for ultrasonication's cavitation effect. As early as 10-minute treatment, UT introduced cracks on potato starch. Increasing sonication exposure from 10 to 30 minutes did not introduce any other depressions on the potato starch surface. The shear force and micro-jet caused these depressions. In a solid-liquid system, cavitation facilitates vapor-filled bubbles that bombard the starch granules [10]. These bubbles undergo rapid disintegration that induces high local velocities of the liquid layer, causing a considerable amount of shear force and micro-jets that erode and create depressions, pits, and fissures onto the granular starch surface [30]. The formation of depressions was similar to previous studies on the ultrasonication of potato starch [9, 11-15]. In addition to this, UT also produced cracks and fissures on starch granules from other botanical sources, including maize [31], wheat [32], cassava [33], and rice [34]. In our set-up, using water as a solvent has the advantage of facilitating cavitation in the starch slurry due to its high surface tension, low viscosity, and low vapor pressure [14].

\subsection{Effects of sonication on the molecular weight distribution of potato starch.}

Starch is a highly branched glucose polymer composed of two main polysaccharides; (1) amylose is mostly linear with a few long-chain branches and having a moderate molecular weight, and amylopectin has many short-chain branches with higher molecular weight [28]. Figure 2 shows the chromatograms of branched raw and sonicated potato starch in terms of retention time and molecular weight distribution. These size-exclusion chromatograms were determined through a pullulan calibration plot as shown in the supplementary data both in Table S1 and Figure S1. Three distinct peaks were observed in the chromatogram of branched 
starch corresponding to high molecular weight amylopectin (Peak 1), intermediate low molecular weight amylopectin (Peak 2), and amylose (Peak 3) [35, 36]. UT revealed no effect on the molecular distribution of potato starch samples with no changes in their amylose/amylopectin components. Amylose/amylopectin peaks show no shifting, suggesting that the ultrasonic parameters of $53 \mathrm{kHz}$ frequency and $180 \mathrm{~W}$ power are insufficient to initiate chain scissoring or break glycosidic linkages. Furthermore, this also implies that UT facilitates mechanical rather than chemical effects by disrupting starch granules. Similarly, Wang and Wang [37] reported that UT did not significantly deteriorate the amylose content of rice starch. In contrast to our results, studies have reported the degradation of potato starch after U.T. Ulbrich et al. (2020) reported that UT $(24 \mathrm{kHz}, 200 \mathrm{~W})$ induced molecular degradation or debranching on the amylopectin component of potato starch. Also, D. Wang et al. [18] observed a decrease in the molecular weight of potato starch treated with ultrasonication having a frequency of $22 \mathrm{kHz}$, and an ultrasonic power of $360 \mathrm{~W}$. Different applied ultrasonic parameters might cause conflict in the effect of UT on potato starch molecular structure.

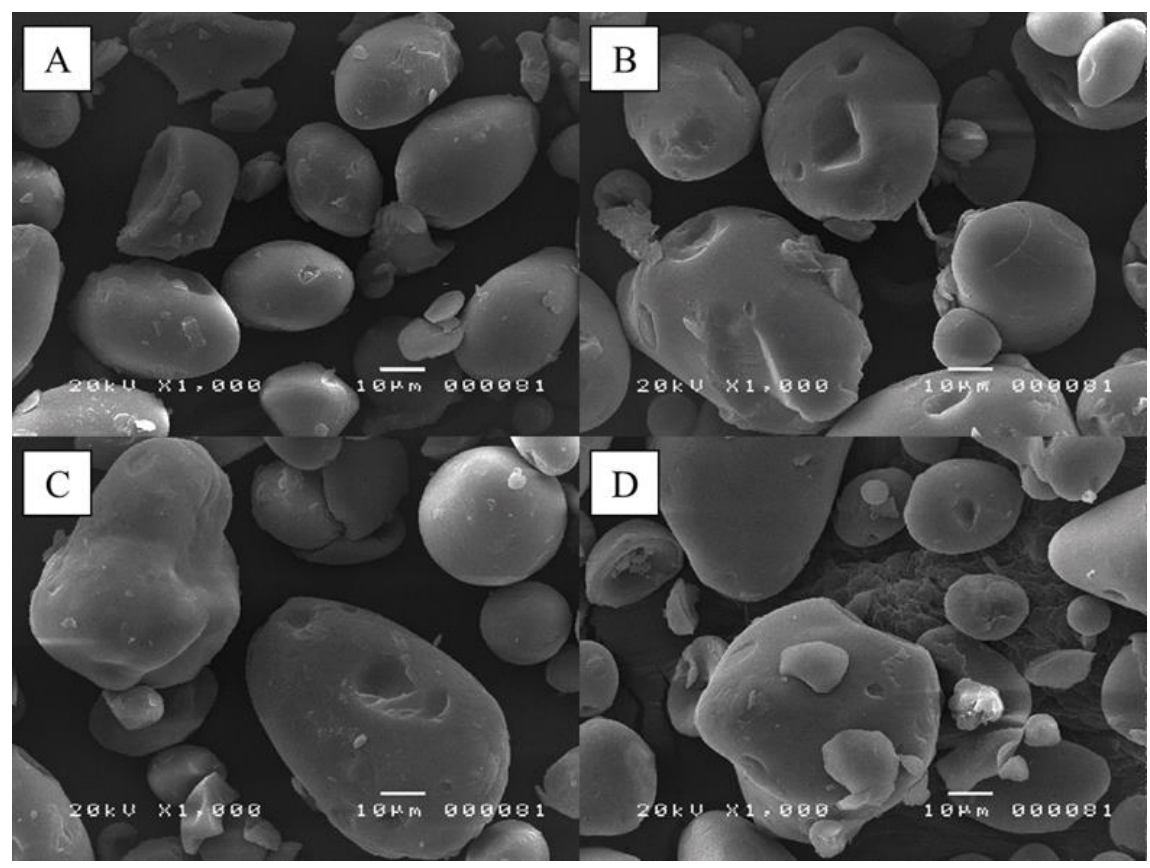

Figure 1. SEM Micrographs of Potato Starch Granules (A) Raw, (B) 10 mins sonication, (C) 20 mins sonication, (D) 30 mins sonication.
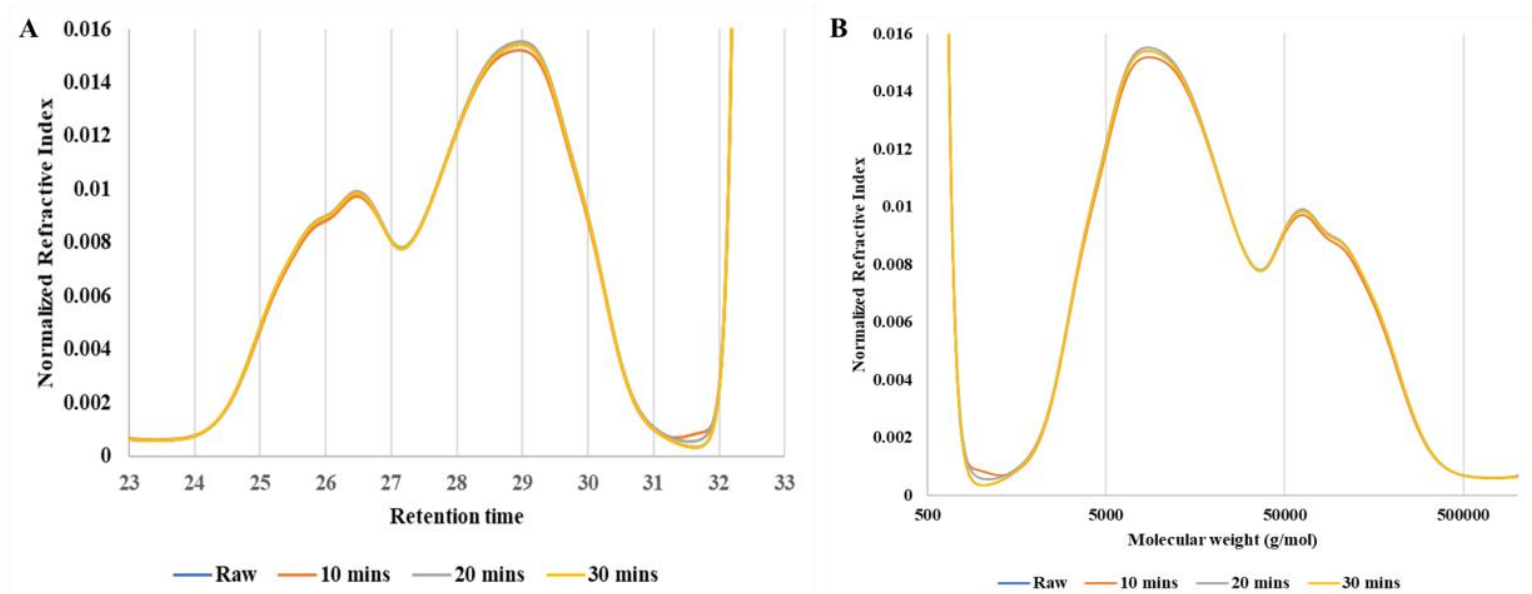

Figure 2. High-performance size-exclusion chromatograms of branched native and sonicated potato starch in terms of (A) retention time and (B) molecular weight. 


\subsection{Effect of sonication on the thermal properties of potato starch.}

Thermal properties of the native and ultrasonic-treated potato starch in different sonication time duration were investigated using DSC. As shown in Table 1, onset temperature $\left(T_{o}\right)$, peak temperature $\left(T_{p}\right)$, and enthalpy change $(\Delta H)$ were determined. An endothermic transition is observed in the DSC curve of potato starches. Starch gelatinization demonstrates the irreversible swelling/melting of the double-helical structure and disorganization of starch crystallites [38]. $T_{o}$ corresponds to the structural degradation of starch, resulting in the release of amylose into the suspension medium. In contrast, $\mathrm{T}_{\mathrm{p}}$ corresponds to the needed temperature where the crystalline region in starch granules confined the hydration of the amorphous region [39]. The enthalpy of gelatinization evaluates crystalline transformation to the amorphous structure of starch, which refers to its molecular order transition [40].

Table 1. Thermal properties of potato starch samples in different sonication times.

\begin{tabular}{l|c|c|c} 
Sample & $\mathbf{T}_{\mathbf{0}}\left({ }^{\circ} \mathbf{C}\right)$ & $\mathbf{T}_{\mathbf{p}}\left({ }^{\circ} \mathbf{C}\right)$ & $\mathbf{\Delta H}(\mathbf{J} / \mathbf{g})$ \\
\hline Control & $66.40 \pm 0.14^{\mathrm{ab}}$ & $77.99 \pm 0.06^{\mathrm{b}}$ & $15.59 \pm 0.93^{\mathrm{a}}$ \\
\hline 10 mins sonication & $65.13 \pm 0.16^{\mathrm{d}}$ & $76.62 \pm 0.11^{\mathrm{a}}$ & $15.49 \pm 0.03^{\mathrm{b}}$ \\
\hline 20 mins sonication & $65.94 \pm 0.59^{\mathrm{ac}}$ & $76.52 \pm 0.11^{\mathrm{a}}$ & $14.45 \pm 1.57^{\mathrm{c}}$ \\
\hline 30 mins sonication & $66.00 \pm 0.29^{\mathrm{bc}}$ & $76.90 \pm 0.18^{\mathrm{c}}$ & $13.78 \pm 2.42^{\mathrm{d}}$
\end{tabular}

Data presented as mean \pm standard deviation of triplicate determinations. Identical superscript letters indicate that there was no significant difference $(\mathrm{P}>0.05)$.

The $T_{o}$ and $T_{p}$ of sonicated samples were slightly lower than the native potato starch. The decrease in $T_{o}$ and $T_{p}$ is associated with the structural degradation of starch, which affects swelling capacity [41]. The $\Delta \mathrm{H}$ of native potato starch was $15.59 \pm 0.93 \mathrm{~J} / \mathrm{g}$. After ultrasonication, the $\Delta \mathrm{H}$ values of 10,20 , and 30 minutes sonication time were $15.49 \pm 0.03$, $14.45 \pm 1.57$, and $13.78 \pm 2.42 \mathrm{~J} / \mathrm{g}$, respectively. The $\Delta \mathrm{H}$ of sonicated potato starch showed a considerable decrease as the sonication time increased. Notetaking that after 30 minutes of sonication, the $\Delta \mathrm{H}$ has $10.3 \%$ lower than the native starch. This observation is similar to other sonicated starch samples, including rice [42], waxy corn [43], and sweet potato [44]. The lowering values of $\Delta \mathrm{H}$ after UT corresponds to the disintegration or destruction of the helical structure of amylopectin in the crystalline region of the starch granules [45]. Starch products with low enthalpy values are more valuable from the energy requirement point of view [46].

\subsection{Effect of sonication on the short order molecular structure of potato starch.}

As a complementary analysis, synchrotron-based Fourier transform infrared spectroscopy (SFTIR) was employed to confirm the organization and degree of modification of the short order molecular structure of the potato starch, specifically its crystalline state after ultrasonication. Similar to the typical FTIR, SFTIR is a non-destructive, highly sensitive, quickly resolved, and highly detective analytical technique for emerging bioanalytical analysis and imaging. Also, SFTIR is used to determine the track real-time chemical information (e.g., molecular structure, composition, and spatial distribution) of a target material [25]. The advantage of synchrotron over typical FTIR is the synchrotron storage ring, which allows emission of light beam accelerated in relativistic speed that manifest high signal-to-noise ratio, high-frequency domain, high flux, polarization, and partial coherence [47]. These properties enhance the IR results by broadening the spectral bandwidth that is almost linear in the entire IR region. The light beam emitted by the storage ring has low divergence and a smaller electron beam [48]. With this, high-quality IR spectral imaging of living samples and real-time chemical 
events was possible at spatial resolutions of $3-10$ microns [49]. Moreover, this technique characterizes biopolymers, including starch [50, 51], cellulose fibers [52], and chitosan [53]. Hence, SFTIR has been widely utilized in polymer chemistry.

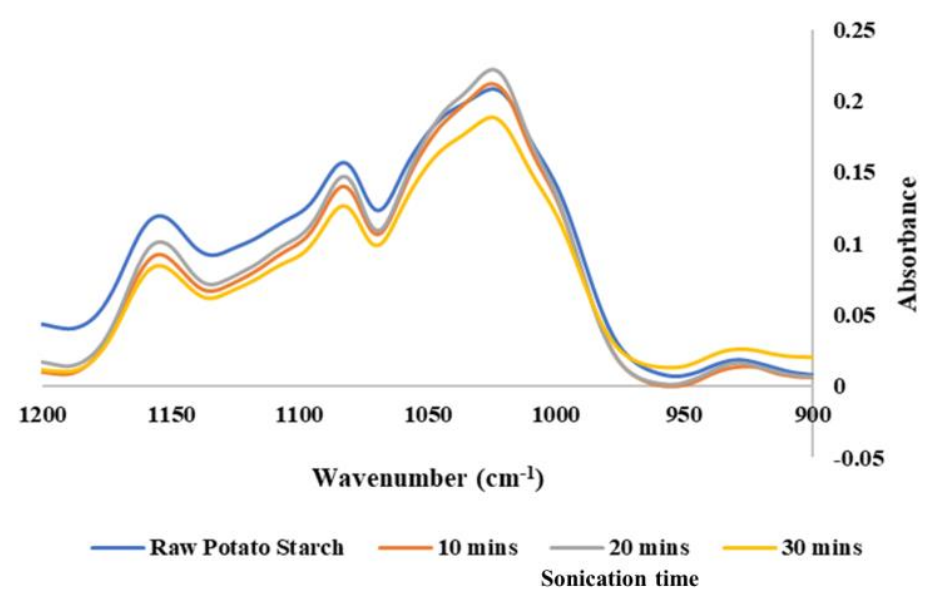

Figure 3. FTIR spectra of Standard and Ultrasonic Treated Potato Starch.

Figure 3 shows the FTIR spectra of native and ultrasonic treated potato starches. The sharp absorption peak within the range of $3250-3500 \mathrm{~cm}^{-1}$ corresponds to -OH stretching can be attributed to the inter-and intra-molecular hydrogen bonding [54]. In this region, native potato starch registered the highest intensity, accounting for the extensive hydrogen bonding present in crystalline and amorphous regions within the starch granules. A probable gelatinization that leads to swelling of potato starch molecules upon preparation can contribute to the peak intensity [38]. A decrease in $\mathrm{OH}$ stretching was observed after 10 minutes of sonication; however, as UT duration increases, the intensity of $\mathrm{OH}$ stretching also increases. This behavior of sonicated starch is associated with loss of crystalline structure and exposure of the - $\mathrm{OH}$ group within the starch molecule [55]. The peaks for $\mathrm{C}-\mathrm{O}, \mathrm{C}-\mathrm{C}$, and $\mathrm{C}-\mathrm{O}-\mathrm{H}$ bond stretching and C-O-H bendings were 1045 and 1022 and $990 \mathrm{~cm}^{-1}$, respectively. Also, there are no changes in the absorption peaks position after sonication; no loss nor formation of absorption peaks was observed, suggesting that there is no new formation or loss of chemical bonds and functional groups. Similarly, Bai et al. (2017) reported that potato starch has no formation or breaking of chemical bonds during UT.

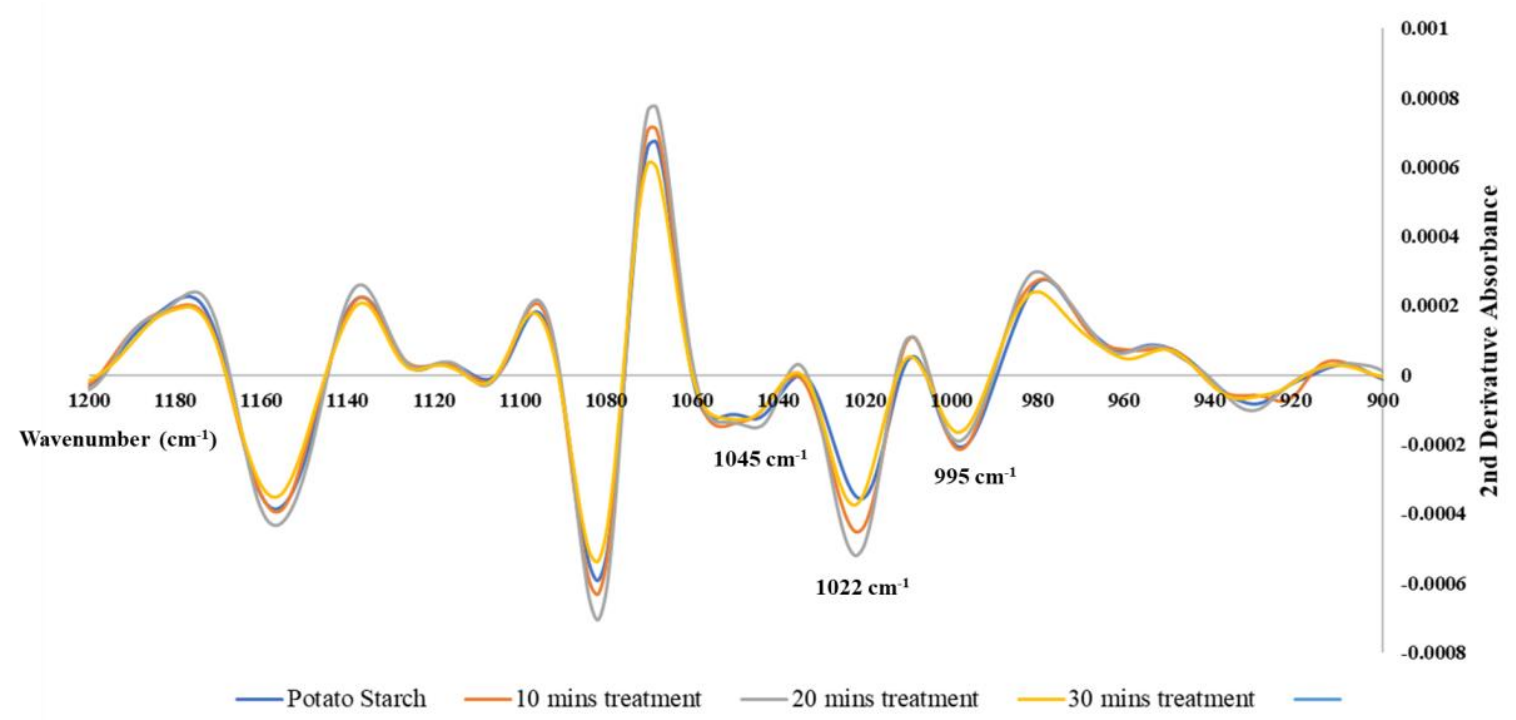

Figure 4. Second Derivative of FTIR spectra of standard and ultrasonic treated potato starch. 
The bands in this region (1100-900 $\left.\mathrm{cm}^{-1}\right)$ are sensitive to changes in crystalline and amorphous regions of starch [23]. Peaks at 1045 and $1022 \mathrm{~cm}^{-1}$ represent the crystalline and amorphous structure, which refers to the amylopectin and amylose of carbohydrate, respectively [56, 57]. While, Lourdin et al. [58] indicated that peaks at 1045 and $995 \mathrm{~cm}^{-1}$ correspond to the crystalline state, while $1022 \mathrm{~cm}^{-1}$ accounts for the amorphous state. To investigate the short-range molecular order of starch granules structure, deconvolution and second derivative in the $1200 \mathrm{~cm}-1$ to $800 \mathrm{~cm}-1$ range of potato starch was obtained. Figure 4 shows the second derivation spectra of the native and ultrasonic treated potato starches. Band ratios at 1022/990 $\mathrm{cm}^{-1}$ and 1045/1022 $\mathrm{cm}^{-1}$ were determined to determine short-range ordered molecular structure,

At $1022 \mathrm{~cm}^{-1}$, native potato starch has a higher intensity than peaks at 1045 and 995 $\mathrm{cm}^{-1}$, indicating that potato starch has a more amorphous conformation than crystalline conformation [59]. The same trend was also observed in the spectra of ultrasonically treated potato starches. However, ultrasonic-treated potato starches registered a higher intensity peak at $1022 \mathrm{~cm}^{-1}$ than the native potato starch. This implied that ultrasonication disrupts the interand intramolecular hydrogen bonding within the starch granules contributing to the increase of amorphous character and a consequent decreasing crystalline character [14, 59, 60].

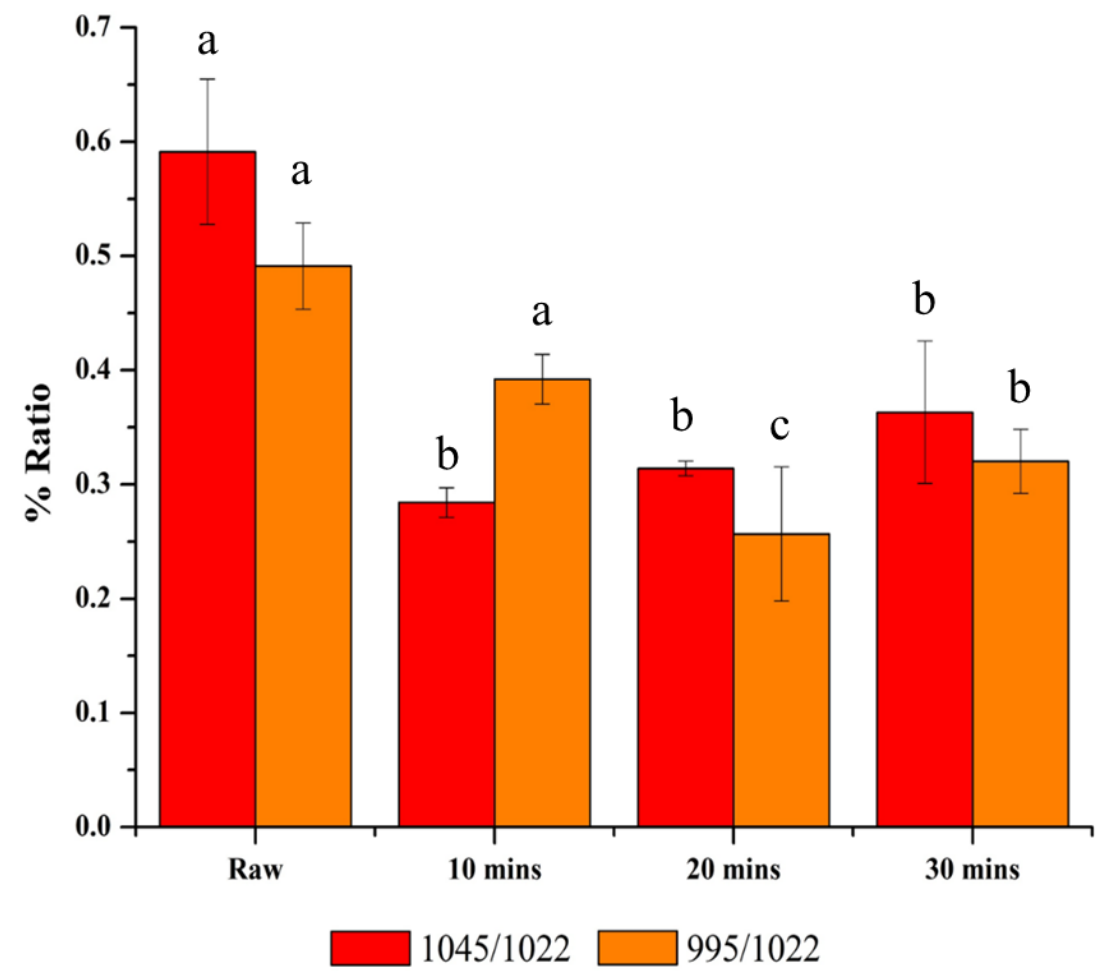

Figure 5. Peak Ratio of the Integrated value of the following FTIR spectrum peaks $\left(1045,1022\right.$, and $\left.995 \mathrm{~cm}^{-1}\right)$ of standard and sonicated potato starch. Data presented as mean \pm standard deviation of triplicate determinations. Identical superscript letters indicate that there was no significant difference $(\mathrm{P}>0.01)$.

As shown in Figure 5, it was confirmed that a considerable decrease in the band ratios implied disruption of the crystalline domains that resulted in the upturn in the amorphous within the starch granule after ultrasonication. The decline in the short-range order of potato starch was confirmed, as shown in the decrease of 1045/1022 value and an increase of 995/1022 value after ultrasonication. This result is complementary to the lower $\Delta \mathrm{H}$ values of ultrasonicated potato starch. Moreover, our FTIR results are in congruence with the report of $\mathrm{Hu}$ et al. [61]; data from conventional FTIR revealed that ultrasonication $(80 \mathrm{kHz})$ lowers $1047 / 1022$ values from 0.92 to 0.84 of potato starch. This change indicated that UT affects the 
short-range order of potato starch. Hence, STIR can be used in studying the crystallinity of ultrasonicated starch samples.

\section{Conclusions}

The ultrasonication of potato starch allows physical modification on the starch granules by creating indentations in the form of depressions, fits, and pressure. Chromatographic identification of the starch components and their molecular weight distribution revealed no chain scissoring or depolymerization of chemical bonds occurred after ultrasonication. Moreover, the thermal properties of ultrasonicated potato starch indicated a disruption of the crystalline structure, as observed in the decrease of onset temperature and enthalpy change. Synchrotron FTIR spectroscopy is an efficient tool in deciphering the molecular structure of sonicated starch. The high spectral resolution and the correction of the baseline variations provided the distinct absorbance bands attributed to the crystalline structure of the native and ultrasonic treated potato starch samples. Hence, SFTIR offers essential information in studying the effect of physical treatment on the starch structure.

\section{Funding}

RNT and APB would like to acknowledge the Philippine Department of Science and Technology-Science Education Institute (DOST-SEI) through the Accelerated Science and Technology Human Resource Development (ASTHRDP) program for the graduate scholarship. APB would like to acknowledge the support of PCIEERD and ADMATEL- ITDI by providing the ADMATEL- EPDC. Research Grant (Batch 9). The authors would like to acknowledge the financial support of the Synchrotron Light Research Institute (Public Organization) and the Office of Vice-Chancellor of Research and Innovation of De La Salle University.

\section{Acknowledgments}

RNT and APB would like to acknowledge Dr. Supatcharee Siriwong and Duangjai Srisamut of SLRI. Beamline 4.1 for their assistance in using FTIR microspectroscopy and Miss Sarintorn Tonghom and Sidaphat Rodthai for their administrative support during our stay at SLRI. Thailand.

\section{Conflicts of Interest}

The authors declare no conflict of interest.

\section{References}

1. Singh, J.; Colussi, R.; McCarthy, O.J.; Kaur, L. Potato Starch and Its Modification. Second Edi.; Elsevier Inc., 2016; pp. 195-247, https://doi.org/10.1016/B978-0-12-800002-1.00008-X.

2. Kong, X. Starches Modified by Nonconventional Techniques and Food Applications. In: Starches for Food Application Chemical, Technological and Health Properties. Pedrosa Silva Clerici, M.T.; Schmiele, M.; Eds.; Elsevier Inc., 2019; pp. 271-295, https://doi.org/10.1016/B978-0-12-809440-2.00007-1.

3. de Oliveira, C.S.; Bet, CD; Bisinella, R.Z.B.; Waiga, L.H.; Colman, T.A.D.; Schnitzler, E. Heat-Moisture Treatment (HMT) on Blends from Potato Starch (PS) and Sweet Potato Starch (SPS). J. Therm. Anal. Calorim. 2018, 133, 1491-1498, https://doi.org/10.1007/s10973-018-7196-9.

4. Han, Z.; An, X.; Juan, S.; Shan, B.; Dong, X. Effects of Pulsed Electric Fields (PEF.) Treatment on Physicochemical Properties of Potato Starch. Innov. Food Sci. Emerg. Technol. 2009, 10, 481-485, https://doi.org/10.1016/j.ifset.2009.07.003. 
5. Villanueva, M.; Lamo, B.D.; Harasym, J.; Ronda, F. Microwave Radiation and Protein Addition Modulate Hydration, Pasting and Gel Rheological Characteristics of Rice and Potato Starches. Carbohydr. Polym. 2018, 201, 374-381; https://doi.org/10.1016/j.carbpol.2018.08.052.

6. Kumar, Y.; Singh, L.; Singh, V.; Patel, A.; Kumar, K. Effect of Microwave Treatment (Low Power and Varying Time) on Potato Starch: Microstructure, Thermo-Functional, Pasting and Rheological Properties. Int. J. Biol. Macromol. 2020, 155, 27-35; https://doi.org/10.1016/j.ijbiomac.2020.03.174.

7. Bie, P.; Pu, H.; Zhang, B.; Su, J.; Chen, L.; Li, X. Structural Characteristics and Rheological Properties of Plasma-Treated Starch. Innov. Food Sci. Emerg. Technol. 2016, 34, 196-204, https://doi.org/10.1016/j.ifset.2015.11.019.

8. Verma, R.; Jan, S.; Rani, S.; Jan, K.; Swer, T. L.; Prakash, K.S.; Dar, M.Z.; Bashir, K. Physicochemical and Functional Properties of Gamma Irradiated Buckwheat and Potato Starch. Radiat. Phys. Chem. 2018, 144, 37-42, https://doi.org/10.1016/j.radphyschem.2017.11.009.

9. Bai, W.; Hébraud, P.; Ashokkumar, M.; Hemar, Y. Investigation on the Pitting of Potato Starch Granules during High Frequency Ultrasound Treatment. Ultrason. Sonochem. 2017, 35, 547-555, https://doi.org/10.1016/j.ultsonch.2016.05.022.

10. Zhu, F. Impact of Ultrasound on Structure, Physicochemical Properties, Modifications, and Applications of Starch. Trends Food Sci. Technol. 2015, 43, 1-17, https://doi.org/10.1016/j.tifs.2014.12.008.

11. Gallant, D.; Degrois, M.; Sterling, C.; Guilbot, A. Microscopic Effects of Ultrasound on the Structure of Potato Starch Preliminary Study. Starch-Stärke 1972, 24, 116-123, https://doi.org/10.1002/star.19720240405.

12. Zuo, Y.; Hébraud, P.; Hemar, Y.; Ashokkumar, M. Quantification of High-Power Ultrasound Induced Damage on Potato Starch Granules Using Light Microscopy. Ultrason. Sonochem. 2012, 19, 421-426, https://doi.org/10.1016/j.ultsonch.2011.08.006.

13. Degrois, M.; Gallant, D.; Baldo, P.; Guilbot, A. The Effects of Ultrasound on Starch Grains. Ultrasonics 1974, 12, 129-131, https://doi.org/10.1016/0041-624X(74)90070-5.

14. Sujka, M.; Jamroz, J. Ultrasound-Treated Starch: SEM and TEM Imaging, and Functional Behaviour. Food Hydrocoll. 2013, 31, 413-419, https://doi.org/10.1016/j.foodhyd.2012.11.027.

15. Sujka, M. Ultrasonic Modification of Starch - Impact on Granules Porosity. Ultrason. Sonochem. 2017, 37, 424-429, https://doi.org/10.1016/j.ultsonch.2017.02.001.

16. Latip, D.N.H.; Samsudin, H.; Utra, U.; Alias, AK Modification Methods toward the Production of Porous Starch: A Review. Crit. Rev. Food Sci. Nutr. 2020, https://doi.org/10.1080/10408398.2020.1789064.

17. Ulbrich, M.; Bai, Y.; Flöter, E. The Supporting Effect of Ultrasound on the Acid Hydrolysis of Granular Potato Starch. Carbohydr. Polym. 2020, 230, https://doi.org/10.1016/j.carbpol.2019.115633.

18. Wang, D.; Hou, F.; Ma, X.; Chen, W.; Yan, L.; Ding, T.; Ye, X.; Liu, D. Study on the Mechanism of Ultrasound-Accelerated Enzymatic Hydrolysis of Starch: Analysis of Ultrasound Effect on Different Objects. Int. J. Biol. Macromol. 2020, 148, 493-500, https://doi.org/10.1016/j.ijbiomac.2020.01.064.

19. Czechowska-Biskup, R.; Rokita, B.; Lotfy, S.; Ulanski, P.; Rosiak, J.M. Degradation of Chitosan and Starch by $360-\mathrm{KHz}$ Ultrasound. Carbohydr. Polym. 2005, 60, 175-184, https://doi.org/10.1016/j.carbpol.2004.12.001.

20. Azhar, A.; Hamdy, M.K. Sonication Effect on Potato Starch and Sweet Potato Powder. J. Food Sci. 1979, 44, 801-804, https://doi.org/10.1111/j.1365-2621.1979.tb08505.x.

21. Pinto, C.C.; Campelo, P.H.; Michielon de Souza, S. Rietveld-Based Quantitative Phase Analysis of B-Type Starch Crystals Subjected to Ultrasound and Hydrolysis Processes. J. Appl. Polym. Sci. 2020, 137, https://doi.org/10.1002/app.49529.

22. Cao, M.; Gao, Q. Effect of Dual Modification with Ultrasonic and Electric Field on Potato Starch. Int. J. Biol. Macromol. 2020, 150, 637-643, https://doi.org/10.1016/j.ijbiomac.2020.02.008.

23. Warren, F.J.; Gidley, M.J.; Flanagan, B.M. Infrared Spectroscopy as a Tool to Characterise Starch Ordered Structure - A Joint FTIR-ATR, NMR, XRD and DSC Study. Carbohydr. Polym. 2016, 139, 35-42, https://doi.org/10.1016/j.carbpol.2015.11.066.

24. Cozzolino, D.; Degner, S.; Eglinton, J. A Review on the Role of Vibrational Spectroscopy as An Analytical Method to Measure Starch Biochemical and Biophysical Properties in Cereals and Starchy Foods. Foods 2014, 3, 605-621, https://doi.org/10.3390/foods3040605.

25. Holman, H.; Bechtel, H.A.; Hao, Z.; Martin, M.C. Synchrotron IR Spectromicroscopy: Chemistry of Living Cells. Anal. Chem. 2010, 82, 8757-8765, https://doi.org/10.1021/ac100991d.

26. McKellar, A.R.W. High-Resolution Infrared Spectroscopy with Synchrotron Sources. J. Mol. Spectrosc. 2010, 262, 1-10, https://doi.org/10.1016/j.jms.2010.04.006.

27. Ellis, G.; Santoro, G.; Gómez, M.A.; Marco, C. Synchrotron IR Microspectroscopy: Opportunities in Polymer Science. IOP Conf. Ser. Mater. Sci. Eng. 2010, 14, https://doi.org/10.1088/1757-899x/14/1/012019.

28. Bertoft, E.; Blennow, A. Structure of Potato Starch. Second Edi.; Elsevier Inc., 2016; https://doi.org/10.1016/B978-0-12-800002-1.00003-0.

29. Cornejo-Ramírez, Y.I.; Martínez-Cruz, O.; Del Toro-Sánchez, C.L.; Wong-Corral, F.J.; Borboa-Flores, J.; Cinco-Moroyoqui, F.J. The Structural Characteristics of Starches and Their Functional Properties. CYTA J. Food 2018, 16, 1003-1017, https://doi.org/10.1080/19476337.2018.1518343. 
30. Li, W.; Gamlath, C. J.; Pathak, R.; Martin, G.J.O.; Ashokkumar, M. Ultrasound - The Physical and Chemical Effects Integral to Food Processing. Ref. Modul. Food Sci. 2019, 329-358, https://doi.org/10.1016/b978-008-100596-5.22679-6.

31. Wang, Y.; Zhang, Z.; He, R.; Mintah, B.K.; Dabbour, M.; Qu, W.; Liu, D.; Ma, H. Proteolysis Efficiency and Structural Traits of Corn Gluten Meal: Impact of Different Frequency Modes of a Low-Power Density Ultrasound. Food Chem. 2021, 344, https://doi.org/10.1016/j.foodchem.2020.128609.

32. Yüksel, Y.; Elgün, A. Determination of the Effect of High Energy Ultrasound Application in Tempering on Flour Quality of Wheat. Ultrason. Sonochem. 2020, 67, https://doi.org/10.1016/j.ultsonch.2020.105129.

33. Airlangga, B.; Sugianto, A. M.; Parahita, G.; Puspasari, F.; Mayangsari, N.E.; Trisanti, P.N.; Sutikno, J.P.; Sumarno, S. Study of Cassava Starch Degradation Using Sonication Process in Aqueous Sodium Chloride. J. Sci. Food Agric. 2021, 101, 2406-2413, https://doi.org/10.1002/jsfa.10864.

34. Yang, W.; Kong, X.; Zheng, Y.; Sun, W.; Chen, S.; Liu, D.; Zhang, H.; Fang, H.; Tian, J.; Ye, X. Controlled Ultrasound Treatments Modify the Morphology and Physical Properties of Rice Starch Rather than the Fine Structure. Ultrason. Sonochem. 2019, 59, https://doi.org/10.1016/j.ultsonch.2019.104709.

35. Grant, L.A.; Ostenson, A.M.; Rayas-Duarte, P. Determination of Amylose and Amylopectin of Wheat Starch Using High Performance Size-Exclusion Chromatography (HPSEC). Cereal Chem. 2002, 79, 771-773, https://doi.org/10.1094/CCHEM.2002.79.6.771.

36. Simsek, S.; Whitney, K.; Ohm, J.B. Analysis of Cereal Starches by High-Performance Size Exclusion Chromatography. Food Anal. Methods 2013, 6, 181-190, https://doi.org/10.1007/s12161-012-9424-4.

37. Wang, L.; Wang, Y.J. Rice Starch Isolation by Neutral Protease and High-Intensity Ultrasound. J. Cereal Sci. 2004, 39, 291-296, https://doi.org/10.1016/j.jcs.2003.11.002.

38. Liu, Q.; Donner, E.; Tarn, R.; Singh, J.; Chung, H.-J. Advanced Analytical Techniques to Evaluate the Quality of Potato and Potato Starch. First Edit.; Singh, J.; Kaur, L. Eds.; Elsevier Ltd., 2009; https://doi.org/10.1016/b978-0-12-374349-7.00008-8.

39. Farooq, A.M.; Dhital, S.; Li, C.; Zhang, B.; Huang, Q. Effects of Palm Oil on Structural and in Vitro Digestion Properties of Cooked Rice Starches. Int. J. Biol. Macromol. 2018, 107, 1080-1085, https://doi.org/10.1016/j.ijbiomac.2017.09.089.

40. Abedi, E.; Pourmohammadi, K. Aggregation Behaviors of Sonicated Tapioca Starch with Various Strengths of Hofmeister Salts under Pre- and Post-Ultrasonic Treatment. Food Hydrocoll. 2020, 105, https://doi.org/10.1016/j.foodhyd.2020.105826.

41. Jamalabadi, M.; Saremnezhad, S.; Bahrami, A.; Jafari, S.M. The Influence of Bath and Probe Sonication on the Physicochemical and Microstructural Properties of Wheat Starch. Food Sci. Nutr. 2019, 7, 2427-2435, https://doi.org/10.1002/fsn3.1111.

42. Zuo, J.; Knoerzer, K.; Mawson, R.; Kentish, S.; Ashokkumar, M. The Pasting Properties of Sonicated Waxy Rice Starch Suspensions. Ultrason. Sonochem. 2009, 16, 462-468, https://doi.org/10.1016/j.ultsonch.2009.01.002.

43. Yang, Q.; Lu, X.X.; Chen, Y.Z.; Luo, Z.G.; Xiao, Z.G. Fine Structure, Crystalline and Physicochemical Properties of Waxy Corn Starch Treated by Ultrasound Irradiation. Ultrason. Sonochem. 2019, 51, 350-358, https://doi.org/10.1016/j.ultsonch.2018.09.001.

44. Wang, H.; Xu, K.; Ma, Y.; Liang, Y.; Zhang, H.; Chen, L. Impact of Ultrasonication on the Aggregation Structure and Physicochemical Characteristics of Sweet Potato Starch. Ultrason. Sonochem. 2020, 63, https://doi.org/10.1016/j.ultsonch.2019.104868.

45. Qiang, H.; Lin, L.; Xiong, F. Ultrasound Effects on the Structure and Chemical Reactivity of Cornstarch Granules. Starch/Staerke 2007, 59, 371-378, https://doi.org/10.1002/star.200700614.

46. Ibanoğlu, Ş.; Özaslan, Z.T.; Ibanoğlu, E. Effects of Ultrasonication and Aqueous Ozonation on Gelatinization and Flow Properties of Potato Starch. Ozone Sci. Eng. 2018, 40, 105-112, https://doi.org/10.1080/01919512.2017.1398634.

47. Hoffner, G.; André, W.; Sandt, C.; Djian, P. Synchrotron-Based Infrared Spectroscopy Brings to Light the Structure of Protein Aggregates in Neurodegenerative Diseases. Rev. Anal. Chem. 2014, 33, 231-243, https://doi.org/10.1515/revac-2014-0016.

48. Ellis, G.; Martin, M. Opportunities and Challenges for Polymer Science Using Synchrotron-Based Infrared Spectroscopy. Eur. Polym. J. 2016, 81, 505-531, https://doi.org/10.1016/j.eurpolymj.2016.02.013.

49. Holman, H.; Martin, M.C.; McKinney, W.R. Synchrotron-Based FTIR Spectromicroscopy: Cytotoxicity and Heating Considerations. J. Biol. Phys. 2003, 29, 275-286, https://doi.org/10.1023/A:1024465414395.

50. Muscat, D.; Tobin, M. J.; Guo, Q.; Adhikari, B. Understanding the Distribution of Natural Wax in StarchWax Films Using Synchrotron-Based FTIR (S-FTIR). Carbohydr. Polym. 2014, 102, 125-135, https://doi.org/10.1016/j.carbpol.2013.11.004.

51. Zhang, N.; Liu, X.; Yu, L.; Shanks, R.; Petinaks, E.; Liu, H. Phase Composition and Interface of StarchGelatin Blends Studied by Synchrotron FTIR Micro-Spectroscopy. Carbohydr. Polym. 2013, 95, 649-653, https://doi.org/10.1016/j.carbpol.2013.03.045.

52. Kavkler, K.; Šmit, Ž.; Jezeršek, D.; Eichert, D.; Demšar, A. Investigation of Biodeteriorated Historical Textiles by Conventional and Synchrotron Radiation FTIR Spectroscopy. Polym. Degrad. Stab. 2011, 96, 1081-1086, https://doi.org/10.1016/j.polymdegradstab.2011.03.011. 
53. Taaca, K. L. M.; Nakajima, H.; Thumanu, K.; Janphuang, P.; Chanlek, N.; Vasquez, M.R. Spectroscopic Studies of Plasma-Modified Silver-Exchanged Zeolite and Chitosan Composites. Mater. Chem. Phys. 2020, 250, https://doi.org/10.1016/j.matchemphys.2020.122980.

54. Wiercigroch, E.; Szafraniec, E.; Czamara, K.; Pacia, M.Z.; Majzner, K.; Kochan, K.; Kaczor, A.; Baranska, M.; Malek, K. Raman and Infrared Spectroscopy of Carbohydrates: A Review. Spectrochim. Acta - Part A Mol. Biomol. Spectrosc. 2017, 185, 317-335, https://doi.org/10.1016/j.saa.2017.05.045.

55. Chung, K.M.; Moon, T.W.; Kim, H.; Chun, J.K. Physicochemical Properties of Sonicated Mung Bean, Potato, and Rice Starches. Cereal Chem. 2002, 79, 631-633, https://doi.org/10.1094/CCHEM.2002.79.5.631.

56. Sevenou, O.; Hill, SE; Farhat, I.A.; Mitchell, J.R. Organisation of the External Region of the Starch Granule as Determined by Infrared Spectroscopy. Int. J. Biol. Macromol. 2002, 31, 79-85, https://doi.org/10.1016/S0141-8130(02)00067-3.

57. van Soest, JJG; Tournois, H.; de Wit, D.; Vliegenthart, J.F.G. Short-Range Structure in (Partially) Crystalline Potato Starch Determined with Attenuated Total Reflectance Fourier-Transform IR Spectroscopy. Carbohydr. Res. 1995, 279, 201-214, https://doi.org/10.1016/0008-6215(95)00270-7.

58. Lourdin, D.; Putaux, J.-L.; Potocki-Véronèse, G.; Chevigny, C.; Rolland-Sabaté, A.; Buléon, A. Crystalline Structure in Starch. In: Starch: Metabolism and Structure. Nakamura, Y. Ed.; 2015; pp. 1-451; https://doi.org/10.1007/978-4-431-55495-0_3.

59. Dankar, I.; Haddarah, A.; Omar, F.E.L.; Pujolà, M.; Sepulcre, F. Characterization of Food Additive-Potato Starch Complexes by FTIR and X-Ray Diffraction. Food Chem. 2018, 260, 7-12, https://doi.org/10.1016/j.foodchem.2018.03.138.

60. Ahmad, M.; Gani, A.; Hassan, I.; Huang, Q.; Shabbir, H. Production and Characterization of Starch Nanoparticles by Mild Alkali Hydrolysis and Ultra-Sonication Process. Sci. Rep. 2020, 10, https://doi.org/10.1038/s41598-020-60380-0.

61. Hu, A.; Li, Y.; Zheng, J. Dual-Frequency Ultrasonic Effect on the Structure and Properties of Starch with Different Size. LWT - Food Sci. Technol. 2019, 106, 254-262, https://doi.org/10.1016/j.lwt.2019.02.040. 


\section{Supplementary Data}

Table S1. Calibration of Pullulan Standard.

\begin{tabular}{|c|c|c|c|c|c|c|}
\hline $\begin{array}{c}\text { Retention } \\
\text { Time (min) }\end{array}$ & $\begin{array}{c}\text { Molecular Weight of } \\
\text { pullulan standards }\end{array}$ & $\begin{array}{l}\text { Calculated Molecular } \\
\text { Weight of starch }\end{array}$ & $\begin{array}{c}\text { LOG } \\
\left(\mathbf{M}_{\text {pullulan }}\right)\end{array}$ & $\begin{array}{c}\text { LOG } \\
\left(\mathbf{M}_{\text {starch }}\right)\end{array}$ & $\begin{array}{c}\text { Found Molecular Weight } \\
\text { of Pullulan standards }\end{array}$ & $\% \mathrm{RSV}$ \\
\hline 23.100 & 642000 & 869210 & 5.81 & 5.94 & 683920.65 & 106.53 \\
\hline 24.033 & 337000 & 456267 & 5.53 & 5.66 & 324957.61 & 96.43 \\
\hline 24.720 & 194000 & 262658 & 5.29 & 5.42 & 187870.63 & 96.84 \\
\hline 25.400 & 107000 & 144868 & 5.03 & 5.16 & 109223.42 & 102.08 \\
\hline 26.491 & 47100 & 63769 & 4.67 & 4.80 & 45751.74 & 97.14 \\
\hline 27.458 & 22000 & 29786 & 4.34 & 4.47 & 21156.87 & 96.17 \\
\hline 28.419 & 9800 & 13268 & 3.99 & 4.12 & 9830.45 & 100.31 \\
\hline \multirow[t]{3}{*}{28.955} & 6100 & 8259 & 3.79 & 3.92 & 6410.77 & 105.09 \\
\hline & & & & \multirow{2}{*}{\multicolumn{2}{|c|}{ Mean }} & 100.07 \\
\hline & & & & & & 4.12 \\
\hline
\end{tabular}

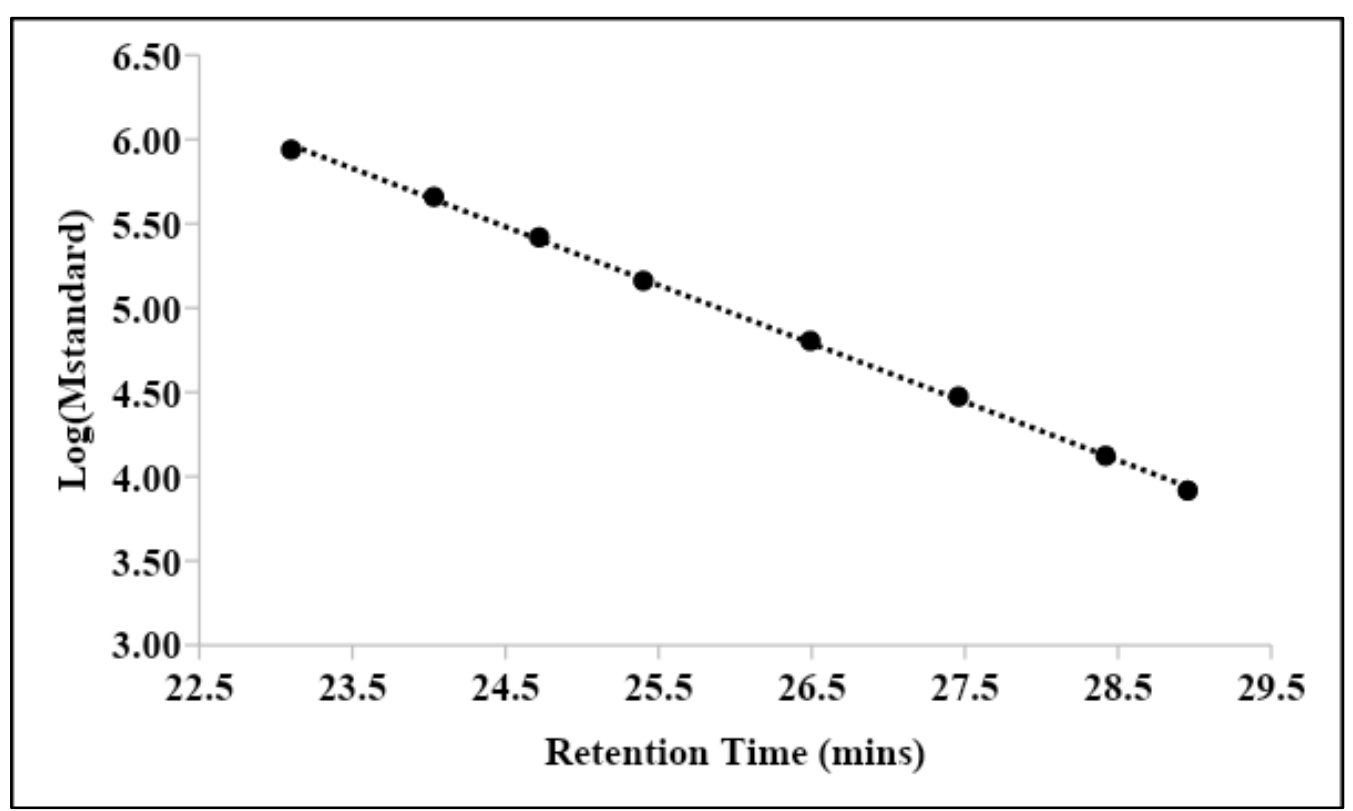

Figure S1. Calibration Curve of Pullulan Standards. 